\section{A cleanish bill of health}

\section{London}

THE system of 'peer review', used to judge research proposals, is showing "signs of strain" as competition for research council grants becomes ever more fierce, but there is "no practicable alternative". That is the sober conclusion of a working group commissioned by the Advisory Board for the Research Councils (ABRC) to examine ways in which the UK research councils' funding decisions could be streamlined and improved.

The group took evidence from more than 150 researchers, and was chaired by Margaret Boden, an expert in artificial intelligence from the University of Sussex and a former ABRC member. Most scientists believe that peer review - where research proposals are judged by the applicants' peers in the scientific community - worked reasonably well until the 1980s. But the past decade has seen a growing number of projects rated highly but still refused funding, as the number of applications for research council grants has risen by more than 15 per cent and the average value of such grants has more than doubled. Not surprisingly, researchers refused funding for alpha-rated projects have begun to question the system.

Quantitative measures of researchers' past output have been put forward as an alternative to peer review. But Boden's group decided that past performance cannot be used as the sole criterion to judge future research promise. In any case, measures such as citation counts may be unreliable - failing to account for variation in publication and citation practices between different disciplines and to distinguish between positive and negative citations. Nevertheless, the report says that the research councils could experiment with the use of citation indices to supplement peer review.

Boden's group also looked at the possibility of holding in-depth interviews with research grant applicants - a technique used by Venture Research International, a small organization set up to fund innovative and unorthodox research. The report says there is some merit in this approach, but the cost is likely to be prohibitive for the research councils, given the huge numbers of grant applications they must process each year.

Despite reaching the depressing conclusion that peer review is inherently fallible, the Boden report suggests a number of improvements to ease the current problems. Disgruntled researchers refused funding will be pleased with the recommendation that more feedback should be given to unsuccesful grant applicants, following the lead of the Economic and Social Research Council, which sends copies of referees' reports to all applicants. The research councils should also publish statements explaining their peerreview systems, the report says.

Boden's group was surprised to find that not all of the research councils have a

\title{
Privatization ahead for BTG
}

\section{London}

A move to privatize the British Technology Group (BTG), the state-owned patents licensing company, was welcomed by the organization last week. On 17 January, Peter Lilley, UK Secretary of State for Trade and Industry, tabled the bill that would, if it became law, turn what has been a government agency into a private company.

With 1989-90 revenues of $£ 29.5$ million and pre-tax profits of $£ 9.5$ million, BTG claims to be the largest technology transfer licensing organization in the world. Privatization will enable BTG to adopt a profile less centred on the United Kingdom. The purpose of BTG is to act as a broker between inventors and the commercial world. In return for 50 per cent of profits, BTG takes on all the costs of patent application, some research and development funding, licensing an invention to industry and any necessary legal action.

This last service is particularly impressive, according to Bob Whelan of the Centre for the Exploitation of Science and Technology, a UK body established just under three years ago to identify scientific developments with possible industrial application. "They've not been afraid to take on the heavyweights like the Pentagon - and beat them", he says. This refers to a case in which the US Department of Defense reached a $\$ 6.1$ million out-of-court settlement with BTG over the right to use a design of hovercraft skirt.

Jeremy Bray, who speaks for the Labour opposition on science, sympathizes with BTG's wish to go it alone. But he thinks that it will still enjoy something of a monopoly. "That they are only able to pass on 50 per cent of earnings to inventors suggests high costs", he says: "a competitor might do better". Whereas one source at the Department of Trade and Industry admitted that BTG has "the lion's share of the business", Whelan is emphatic that BTG will soon meet more competition once its activities are expanded abroad to the United States and Japan.

Henry Gee computerized database to keep track of referees used in peer review. The research councils should all establish databases on active researchers and their suitability as referees, the report concludes. These should be compatible, so the research councils can tap in to one another's resources.

The peer-review system has been accused of discriminating against unorthodox proposals and young researchers with no proven track record. The Boden group found no hard evidence of this, but suggests that money could be earmarked for young researchers and novel projects.

Peter Aldhous

ANIMAL EXPERIMENTS

\section{UK government funds humane research \\ London}

THE British Home Office has announced that an extra $£ 145,000$ will be spent this year on research to develop alternatives to animal experiments (see Correspondence page 274). The new money supplements an existing scheme worth about $£ 70,000$ a year, and $£ 30,000$ in outside donations administered by the Home Office.

Michael Balls, from the Fund for the Replacement of Animals in Medical Experiments (FRAME), welcomes the new money, but says it is "trivial" in the context of government expenditure. The government has yet to demonstrate "a genuine commitment" to reducing animal experiments, he says. FRAME receives about $£ 250,000$ a year from industry, charitable trusts and the European Communities.

PRIZES

Peter Aldhous

\section{Japan Prize winners \\ Tokyo}

THIS year's winners of the lucrative Japan Prize - Japan's answer to the Nobel Prize - are Jacques-Louis Lions, chairman of analysis and systems control at the Collège de France and president of the National Centre for Space Studies (CNES), France, and John Julian Wild, director of the Medico-Technological Research Institute of Minneapolis in the United States. Each will receive a cash prize of $¥ 50$ million $(\$ 370,000)$.

Lions, who is 62 , is given the award by the Science and Technology Foundation of Japan in this year's category of applied mathematics for his pioneering research in the field of analysis and control of distributed systems and for his contributions to development of applied analysis. Wild, 72, receives his award in "imaging techniques in medicine" for his development of ultrasound imaging. The awards will be presented in Tokyo in April.

David Swinbanks 